
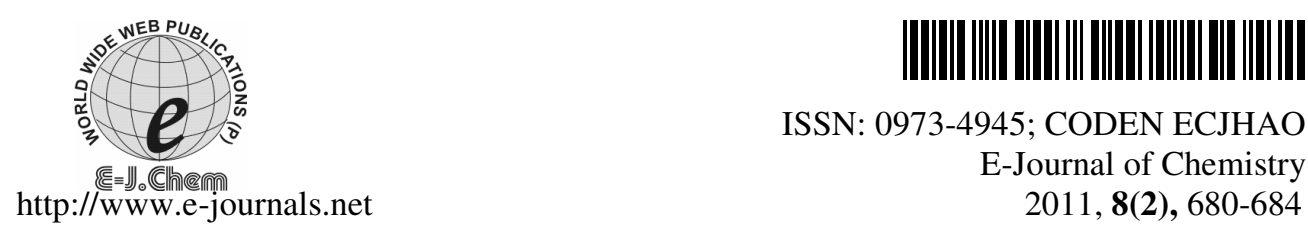

ISSN: 0973-4945; CODEN ECJHAO

E-Journal of Chemistry $2011,8(2), 680-684$

\title{
Gamma Radiolysis Studies of Aqueous Solution of Brilliant Green Dye
}

\author{
D. V. PARWATE and S. S. MANKAR \\ Department of Chemistry \\ Rashtrasant Tukadoji Maharaj Nagpur University Nagpur-440 033, India \\ dilipparwate@rediffmail.com
}

Received 13 May 2010; Revised 27 July 2010; Accepted 27 August 2010

\begin{abstract}
The effect of $\gamma$-radiation on colour intensity of aqueous solution of Brilliant Green has been investigated at two different concentrations. The degradation of Brilliant Green (BG) has also been investigated in presence of suspended $\mathrm{ZnO}$, by adding different amounts of $\mathrm{ZnO}$. Simultaneously the conductance and $\mathrm{pH}$ of each solution system were measured before and after $\gamma$-irradiation. All the $\gamma$-irradiations were performed at a dose rate of $0.60 \mathrm{kGyhr}^{-1}$ in GC-900. The maximum dose required for the complete degradation of the dye was found to be $0.39 \mathrm{kGy}$. G(-dye) values were found to decrease with increase in gamma dose and were in the range $4.26-12.81$. The conductance $(7.6-25.3 \mu \mathrm{S})$ and $\mathrm{pH}$ values increased marginally with dose for both the concentrations. The rate of decolouration was found to be high at lower doses and the efficiency of dye removal was higher at low concentration of the dye. This may be attributed to the presence of reaction by-products from the destruction of parent compound build up and compete for reaction intermediate species. The rate of reaction and rate constants were calculated and it was found that the degradation reaction follows first order kinetics. It was found that the decolouration percentage was more in dye systems in absence of $\mathrm{ZnO}$.
\end{abstract}

Keywords: Radiolysis, G-value, Kinetics, Brilliant Green, Zinc oxide

\section{Introduction}

Dyes are the compounds that have been used extensively in various industries and particularly in textile industries. Water plays important role in dyeing process and therefore waste water has intense colours. The ordinary treatment processes do not degrade the majority of dyes present in waste water from the textile industries. In such a case ionizing radiations seems to be a promising method. This is because the use of $\gamma$-radiation can be intensified in aqueous solution of dyes ${ }^{1-3}$. Other technique comprises the use of advanced oxidation process for the decolouration of textile waste water taken from different textile plants. The advanced oxidation processes making use of ozone, $\gamma$-radiation, hydrogen peroxide and UV-radiation have given good decolouration results ${ }^{4}$. 
The effect of $\gamma$-radiation on colour intensity of aerated, oxygenated, $\mathrm{N}_{2}, \mathrm{~N}_{2} \mathrm{O}$ saturated aqueous solution of dyes have also been reported ${ }^{5,6}$. Mansoori et $a l^{7}{ }^{2}$ have studied the photographic bleaching of Rhodamine-B (Rh-B) over the zinc powder in presence of light. Sharma et al. ${ }^{8}$ investigated the photocatalytic bleaching of Orange-G dye in aqueous $\mathrm{ZnO}$ solutions. Magesh et al. ${ }^{9}$ have reported the photocatalytic behaviour of $\mathrm{CeO}_{2}-\mathrm{TiO}_{2}$ system for the degradation of Methylene blue. Panwar et al. ${ }^{10}$ investigated the use of zirconium phosphate as a photocatalyst in a photobleacing of Eriochrme Black-T, Methylene Blue and Malchite Green. In the present work we are reporting degradation or decolouration of Brilliant Green dye in its aqueous solutions in presence and absence of $\mathrm{ZnO}$ at different concentrations.

\section{Experimental}

The dose rate of GC-900 was determined using Fricke dosimeter ${ }^{11}$. Brilliant Green ${ }^{12}$ (abbreviated as BG) (C.I. 42020), molecular weight $385.55 \mathrm{~g} / \mathrm{mole}\left(\mathrm{C}_{27} \mathrm{H}_{33} \mathrm{~N}_{2}\right)$, obtained from B.D.H. was used without further purification. Other reagents used were of analytical grade and all the solutions were prepared in double distilled water in all glass apparatus. Absorbances were measured on Spectronic 20 D+/ GCB Cintra 2e spectrophotometer.

The $\lambda_{\max }$ of BG was obtained by preparing stock solution of. $5.23 \times 10^{-4} \mathrm{M}$ which was diluted to give $0.53 \times 10^{-5} \mathrm{M}, 1.55 \times 10^{-5} \mathrm{M}$ and $2.6 \times 10^{-5} \mathrm{M}$ solutions. For the preparation of calibration plot, the solutions of concentration range $5.2 \times 10^{-6} \mathrm{M}$ to $12.5 \times 10^{-6} \mathrm{M}$ were prepared and absorbance of each solution systems was measured at $\lambda_{\max }=630 \mathrm{~nm}$. The stability of dye was checked by measuring the absorbance of the solution after every half an hour. This was continued till there was a change in absorbance of about $10 \%$.

For the present work, BG dye was studied in high as well as low concentrations $1.84 \times 10^{-5} \mathrm{M}$ and $0.92 \times 10^{-5} \mathrm{M}$ (i.e 0.018 and $0.0092 \mathrm{mM}$ ). The dye solution $(10 \mathrm{~mL}$ ) was taken in a glass tube with B-24 standard joints and irradiated at different doses. The irradiations were carried out in ${ }^{60}$ Co Gamma Chamber-900 (GC-900) housed in Department of Chemistry, RTM Nagpur University, India. The dose rate during the study was $0.60 \mathrm{kGyhr}^{-1}$. The irradiations were carried out at room temperature (around $3 \pm 1{ }^{\circ} \mathrm{C}$ ). The conductance and $\mathrm{pH}$ of the solutions were measured before and after irradiation on ELICO CM-180 conductometer and ELICO LI-63 pH meter respectively. The systems mentioned above have also been irradiated by adding $0.1 \mathrm{~g}, 0.2 \mathrm{~g}$ and $0.4 \mathrm{~g}$ of $\mathrm{ZnO}$. The solutions were centrifuged for $10 \mathrm{~min}$ after irradiation to settle the suspended particles of $\mathrm{ZnO}$ and the absorbance, conductance and $\mathrm{pH}$ values were measured.

\section{Results and Discussion}

The $\lambda_{\max }$ of BG dye was found to be at $630 \mathrm{~nm}$. The experimental and calculated parameters are given in Tables 1 to 4 for different concentrations. The radiation chemical yield of BG dye, $\mathrm{G}$ (-BG) decreased with increase in dose for both the concentrations and were in the range of 4.26-12.81. The rate of decolouration was found to be higher at lower doses (in both the cases i.e. the systems with and without $\mathrm{ZnO}$ ). The maximum degradation was found in case of $0.2 \mathrm{~g}$ of $\mathrm{ZnO}$ for the systems with $\mathrm{ZnO}$. The aqueous systems required dose $0.39 \mathrm{kGy}$ for $1.84 \times 10^{-5} \mathrm{M}$ and $0.17 \mathrm{kGy}$ for $0.92 \times 10^{-5} \mathrm{M}$ BG solution while the systems with $0.2 \mathrm{~g}$ 0f $\mathrm{ZnO}$ require $0.34 \mathrm{kGy}$ for $1.84 \times 10^{-5} \mathrm{M}$ and $0.14 \mathrm{kGy}$ for $0.92 \times 10^{-5} \mathrm{M}$ BG solution. This shows that the required gamma dose for the system with $\mathrm{ZnO}$ was less. The efficiency of dye removal is higher at low concentrations. The explanation for this is probably that the presence of reactions by-products from the destruction of parent compound build up and compete for reaction intermediates species, acting as scavengers of the reactive species ${ }^{13}$. 
Table 1. Experimental and calculated values for $\left(1.84 \times 10^{-5} \mathrm{M}\right)$ Brilliant green dye

\begin{tabular}{|c|c|c|c|c|c|c|}
\hline $\begin{array}{l}\text { Dose } \\
(\mathrm{kGy})\end{array}$ & $\begin{array}{c}\text { Concentration } \\
10^{-5}, \mathrm{M}\end{array}$ & $\begin{array}{c}\text { Conductance, } \\
200 \mu \mathrm{s}\end{array}$ & $\mathrm{pH}$ & $\mathrm{G}, \mathrm{BG}$ & $\begin{array}{l}\text { Rate of reaction } \\
10^{-5}, \text { moles } \mathrm{dm}^{3} \mathrm{~h}^{-1}\end{array}$ & $\begin{array}{c}\text { Reaction } \\
\text { constant, } \\
\mathrm{kGy}^{-1}\end{array}$ \\
\hline Unirradiated & 1.84 & 19.0 & 6.5 & 0 & 0 & 0 \\
\hline 0.0563 & 1.25 & 10.5 & 6.4 & 10.15 & 7.11 & 6.87 \\
\hline 0.1126 & 0.75 & 14.0 & 6.4 & 9.38 & 6.57 & 7.97 \\
\hline 0.1689 & 0.475 & 16.5 & 6.4 & 7.80 & 5.46 & 8.01 \\
\hline 0.2252 & 0.25 & 20.1 & 6.4 & 6.88 & 4.82 & 8.86 \\
\hline 0.2816 & 0.20 & 25.2 & 6.4 & 5.58 & 3.90 & 7.88 \\
\hline 0.3379 & 0.125 & 29.3 & 6.2 & 4.90 & 3.43 & 7.95 \\
\hline 0.3942 & 0.10 & 30.1 & 5.9 & 4.26 & 2.98 & 7.39 \\
\hline
\end{tabular}

Table 2. Experimental and calculated values for $\left(0.92 \times 10^{-5} \mathrm{M}\right)$ Brilliant green dye

\begin{tabular}{ccccccc}
\hline $\begin{array}{c}\text { Dose, } \\
\mathrm{kGy}\end{array}$ & $\begin{array}{c}\text { Concentration Conductance, } \\
10^{-5} \mathrm{M}\end{array}$ & $200 \mu \mathrm{s}$ & $\mathrm{pH}$ & $\mathrm{G}, \mathrm{BG}$ & $\begin{array}{c}\text { Rate of reaction } \\
10^{-5}, \text { moles } \\
\mathrm{dm}^{3} \mathrm{~h}^{-1}\end{array}$ & $\begin{array}{c}\text { Reaction } \\
\text { constant } \\
\mathrm{kGy}^{-1}\end{array}$ \\
\hline $\begin{array}{c}\text { Unirradiated } \\
0.0563\end{array}$ & 0.92 & 7.6 & 6.2 & 0 & 0 & 0 \\
0.1126 & 0.375 & 7.8 & 6.2 & 9.38 & 6.56 & 15.94 \\
0.1689 & 0.175 & 9.2 & 6.4 & 6.41 & 4.49 & 14.73 \\
\hline
\end{tabular}

Table 3. Experimental and calculated values for $\left(1.84 \times 10^{-5} \mathrm{M}\right)$ Brilliant green dye with $0.2 \mathrm{~g}$ $\mathrm{ZnO}$

\begin{tabular}{ccccccc}
\hline $\begin{array}{c}\text { Dose, } \\
\mathrm{kGy}\end{array}$ & $\begin{array}{c}\text { Concentration } \\
10^{-5} \mathrm{M}\end{array}$ & $\begin{array}{c}\text { Conductance, } \\
200 \mu \mathrm{s}\end{array}$ & $\mathrm{pH}$ & $\mathrm{G}, \mathrm{BG}$ & $\begin{array}{c}\text { Rate of reaction } \\
10^{-5} \text { moles } \\
\mathrm{dm}^{3} \mathrm{~h}^{-1}\end{array}$ & $\begin{array}{c}\text { Reaction } \\
\text { constant, } \\
\mathrm{kGy}^{-1}\end{array}$ \\
\hline $\begin{array}{c}\text { Unirradiated } \\
0.1126\end{array}$ & 1.84 & 24.0 & 7.1 & 0 & 0 & 0 \\
0.2252 & 0.35 & 42.3 & 7.0 & 12.81 & 8.98 & 14.74 \\
0.3379 & 0.30 & 35.2 & 7.0 & 6.66 & 4.67 & 8.05 \\
\hline
\end{tabular}

Table 4. Experimental and calculated values for $\left(0.92 \times 10^{-5} \mathrm{M}\right)$ Brilliant green dye with $0.2 \mathrm{~g}$ $\mathrm{ZnO}$

\begin{tabular}{ccccccc}
\hline $\begin{array}{c}\text { Dose, } \\
\mathrm{kGy}\end{array}$ & $\begin{array}{c}\text { Concentration Conductance, } \\
10^{-5} \mathrm{M}\end{array}$ & $\begin{array}{c}\text { 200 } \mu \mathrm{s} \\
\mathrm{nH} \text { G, BG }\end{array}$ & $\begin{array}{c}\text { Rate of reaction } \\
10^{-5} \text { moles } \\
\mathrm{dm}^{3} \mathrm{~h}^{-1}\end{array}$ & $\begin{array}{c}\text { Reaction } \\
\text { constant, } \\
\mathrm{kGy}^{-1}\end{array}$ \\
\hline $\begin{array}{c}\text { Unirradiated } \\
0.0446\end{array}$ & 0.92 & 19.8 & 7.0 & 0 & 0 & 0 \\
0.0898 & 0.175 & 21.6 & 7.2 & 11.79 & 8.25 & 20.12 \\
0.1351 & 0.125 & 24.9 & 7.2 & 7.99 & 5.60 & 18.48 \\
\hline
\end{tabular}

Figure 1 and 2 show variation in G-value for aqueous systems. Similarly Figure 3 and 4 show variation in $\mathrm{G}$-value for systems with $\mathrm{ZnO}$. The addition of $\mathrm{ZnO}$ in aqueous dye solutions shows odd behavior in decrease in G-values and absorbance. 


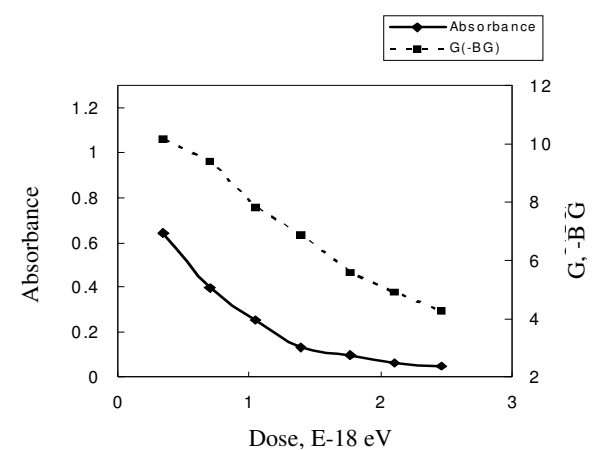

Figure 1. Variation in G-value and absorbance with dose for $\left(1.84 \times 10^{-5} \mathrm{M}\right)$ Brilliant Green

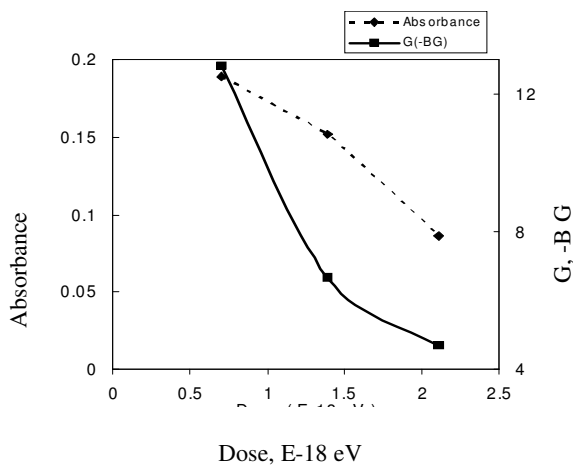

Figure 3. Variation in G-value and Gvalue and absorbance for $\left(1.84 \times 10^{-5} \mathrm{M}\right)$ Brilliant Green with $0.2 \mathrm{~g} \mathrm{ZnO}$

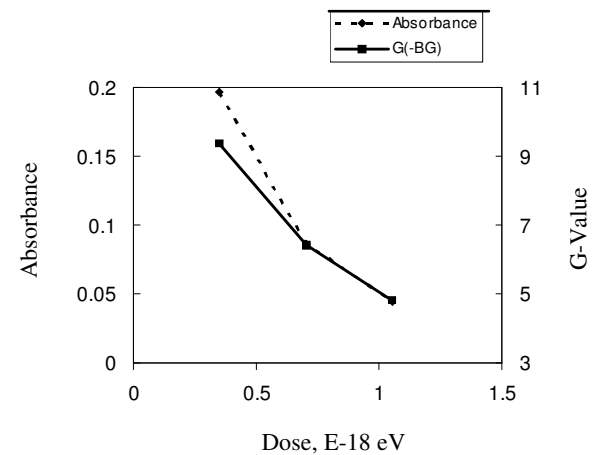

Figure 2. Variation in G-value and absorbance with dose for $\left(0.92 \times 10^{-5} \mathrm{M}\right)$ Brilliant Green

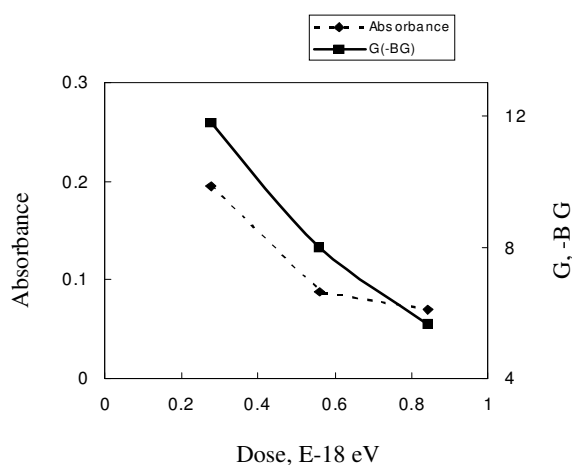

Figure 4. Variation in absorbance for $\left(0.92 \times 10^{-5} \mathrm{M}\right)$ Brilliant Green with $0.2 \mathrm{~g}$ $\mathrm{ZnO}$

The conductance was found to be increasing for both aqueous as well as the aqueous systems with $\mathrm{ZnO}$. The conductance of dyes solutions did not change very much after irradiation because dyes do not form ions when dissolved in water. The conductance values were found to be in the range of $7.6-42.3 \mu \mathrm{S}$. It was observed that the $\mathrm{pH}$ of systems did not change significantly. It was slightly decreased for $1.84 \times 10^{-5} \mathrm{M}$ while it increased with dose for $0.92 \times 10^{-5} \mathrm{M}$ BG solution. The $\mathrm{pH}$ values did not change for $1.84 \times 10^{-5} \mathrm{M}$ with $0.2 \mathrm{~g}$ of $\mathrm{ZnO}$ while slightly increased for $0.92 \times 10^{-5} \mathrm{M} \mathrm{BG}$ with $0.2 \mathrm{~g} \mathrm{ZnO}$.

It was found that the degradation reactions are of first order reactions. In case of degradation kinetics in the present work, the rate of reaction and reaction constants were calculated $^{3}$ using following expressions (for first order reaction).

$$
\begin{gathered}
\text { Rate of reaction }=\frac{\text { Decrease in concentration }}{\text { Time }} \\
k=\frac{\ln \mathrm{C}_{0}-\ln \mathrm{C}}{\mathrm{D}}
\end{gathered}
$$

Where,

$k=$ Reaction constant, $\mathrm{C}_{0}=$ Initial concentration (before irradiation), $\mathrm{C}=$ Residual concentration (after irradiation), $\mathrm{D}=$ Absorbed dose $(\mathrm{eV}), \mathrm{t}=$ Time (hours) 
The rate of degradation reaction was found to decrease with increase in gamma dose. It decreased from $7.1 \times 10^{-5}-2.98 \times 10^{-5}$ moles $\mathrm{dm}^{3} \mathrm{~h}^{-1}$ for $1.84 \times 10^{-5} \mathrm{M}$ while $6.56 \times 10^{-5}$ $3.38 \times 10^{-5}$ moles $\mathrm{dm}^{3} \mathrm{~h}^{-1}$ for $0.92 \times 10^{-5} \mathrm{M}$ aqueous systems. It was found to decrease from $8.98 \times 10^{-5}-3.28 \times 10^{-5}$ moles $\mathrm{dm}^{3} \mathrm{~h}^{-1}$ for $1.84 \times 10^{-5} \mathrm{M}$ of BG with $0.2 \mathrm{~g}$ of $\mathrm{ZnO}$ and $8.25 \times 10^{-5}$ $-3.98 \times 10^{-5}$ moles $\mathrm{dm}^{3} \mathrm{~h}^{-1}$ for $0.92 \times 10^{-5} \mathrm{M}$ of BG with $0.2 \mathrm{~g} \mathrm{ZnO}$.

The reaction rate constants ${ }^{14}$ were calculated graphically as well as using expression (2). The reaction constants were in the range of $6.87-20.04 \mathrm{kGy}^{-1}$ (calculated using expression 2) and the values calculated graphically were in the range $6.00-15.09 \mathrm{kGy}^{-1}$, showing a good correlation.

\section{Conclusion}

The G-values decrease regularly as the absorbed dose increases. The decolouration percentage was near about same in dye systems in absence and presence of $\mathrm{ZnO}$. No significant changes in conductance and $\mathrm{pH}$ values were observed after $\gamma$-irradiation. The degradation of dyes using $\gamma$-irradiation can be used for decolouration of wastewater.

\section{Acknowledgment}

The authors are thankful to the Head, Department of Chemistry, RTMN University, for providing necessary facilities.

\section{References}

1. Ayed S. AL-Shihri and EL-Assy N B, JKAU Sci, 2003, 15, 99-114.

2. Suzuki N, Nagai T, Hotta H and Washino M, Bull Chem Soc Japan, 1975, 48(7), 2158-2163.

3. Al-Gorair A S, Al-Mutabagani L A and Al-Suhybani A, J Saudi Chem Soc., 2007, 11(1), 163-172.

4. Lech Kos and Jan Perkowski, Fibres \& Textiles in Eastern Europe, 2003, 11(4), 43.

5. Abdel Rahim F and Eid S A, Souka N and McLaughlin W L, Int J Radiat Appl Instrum Part C, 1986, 27(3), 211-217.

6. Dilek Olpan, Olgun Güven, Erzsébet Takács, László Wojnárovits and Katalin Dajka, Radiat Phys Chem., 2003, 67(3-4), 531-534.

7. Mansoori Riyaj A, Kothari Sharad and Ameta Rameshwar, J Indian Chem Soc, 2004, 81, 335-337.

8. Sharma A., Rao P, Mathur R P and Ameta S.C, Hung J Ind Chem., 1995, 23, 31.

9. Magesh G, Vishwanath B, Vishwanath R P and Tadarjan T K, Indian J Chem., 2009, 48A, 480-488.

10. Panwar O P, Kumar Anil, Paliwal Mukesh, Ameta Rameshwar and Ameta Suresh C, Bull Catalysis Soc India, 2008, 7, 105-110.

11. Arnikar H J, Essentials of Nuclear Chemistry, New Age International (p) Ltd., New Delhi, $4^{\text {th }}$ Ed, 1995.

12. Venkatraman K, The Chemistry of Synthetic Dyes, Vol IV, National Laboratory Pune, India, 1971.

13. Spinks J W T and Woods R J, An Introduction to Radiation Chemistry, John Wiley and Sons, New York, 1975.

14. Zhang Shu-Juan, Han-Qing Yu and Yuan Zhao, Water Res., 2005, 39(5), 839-846. 


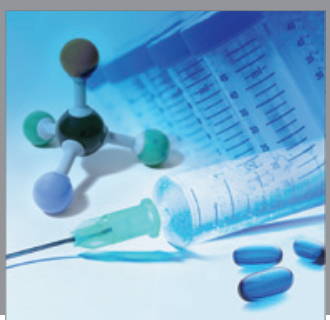

International Journal of

Medicinal Chemistry

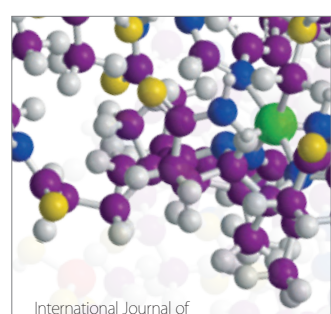

Carbohydrate Chemistry

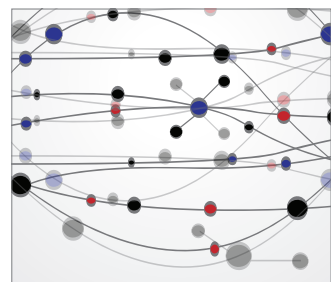

The Scientific World Journal
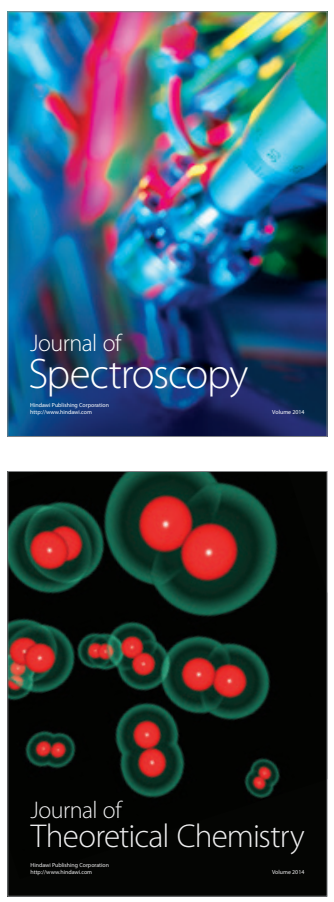
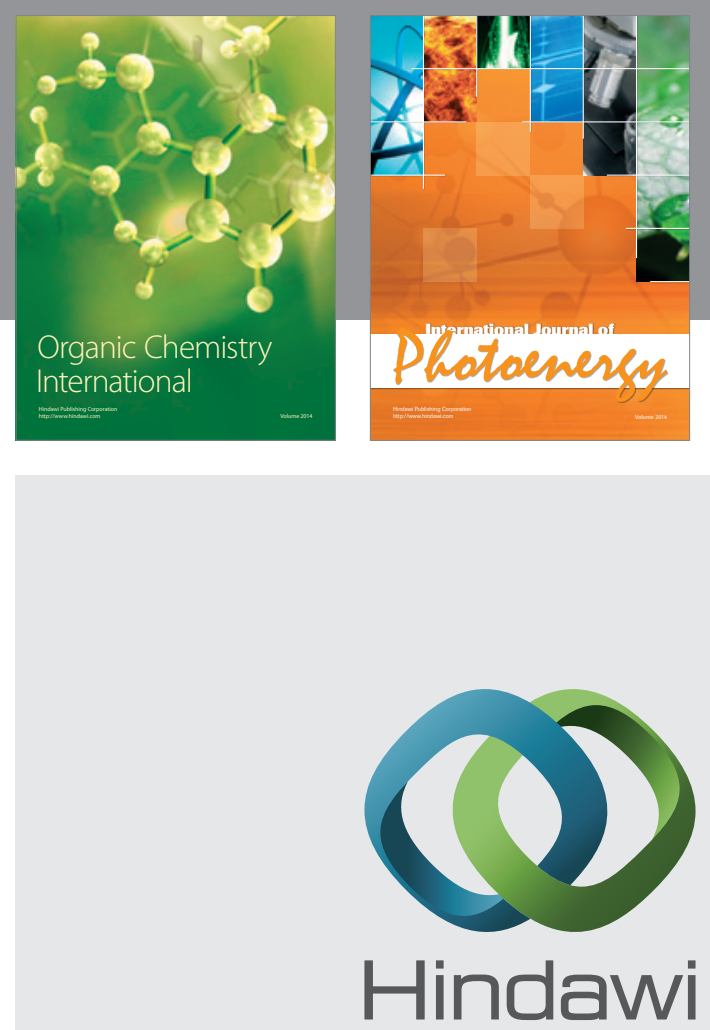

Submit your manuscripts at

http://www.hindawi.com
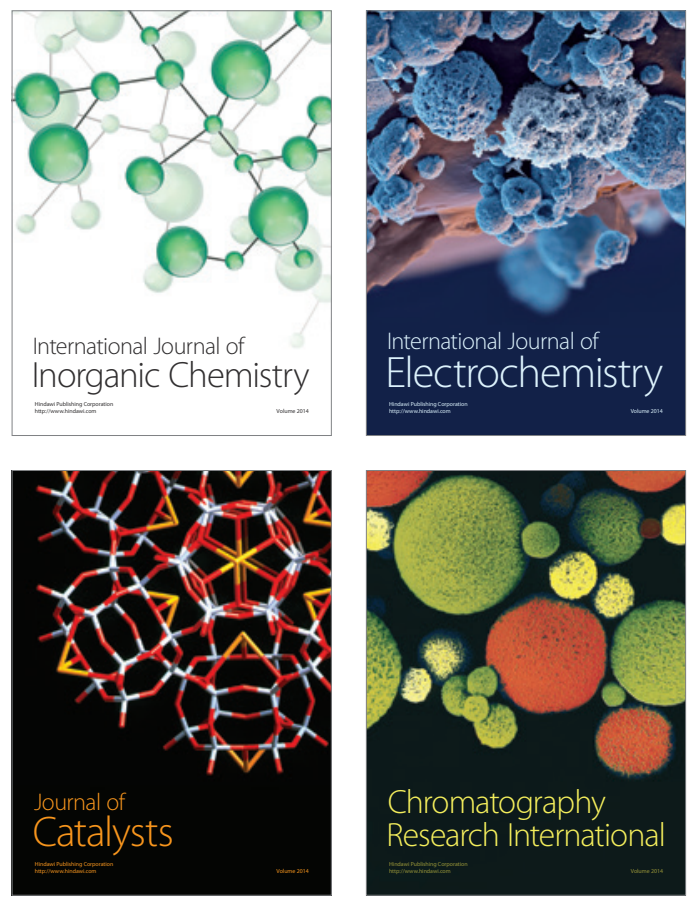
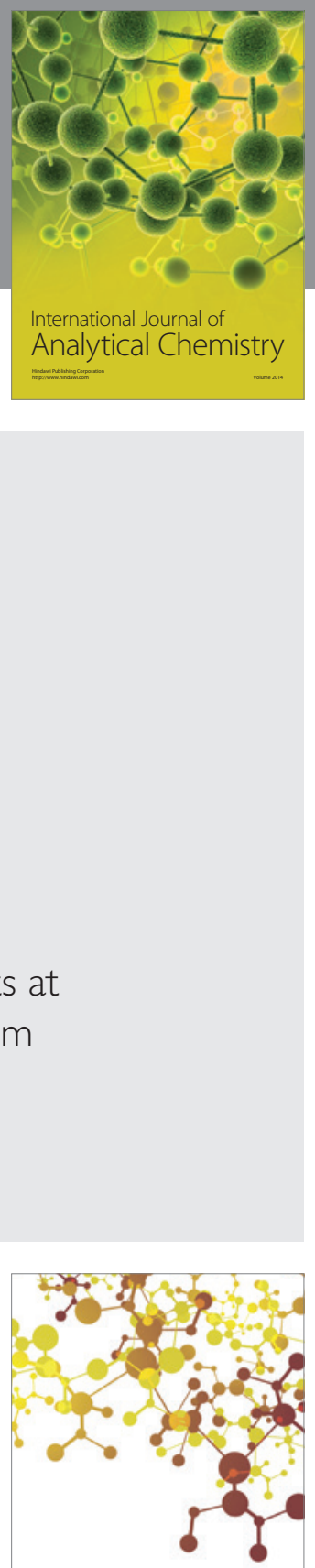

Journal of

Applied Chemistry
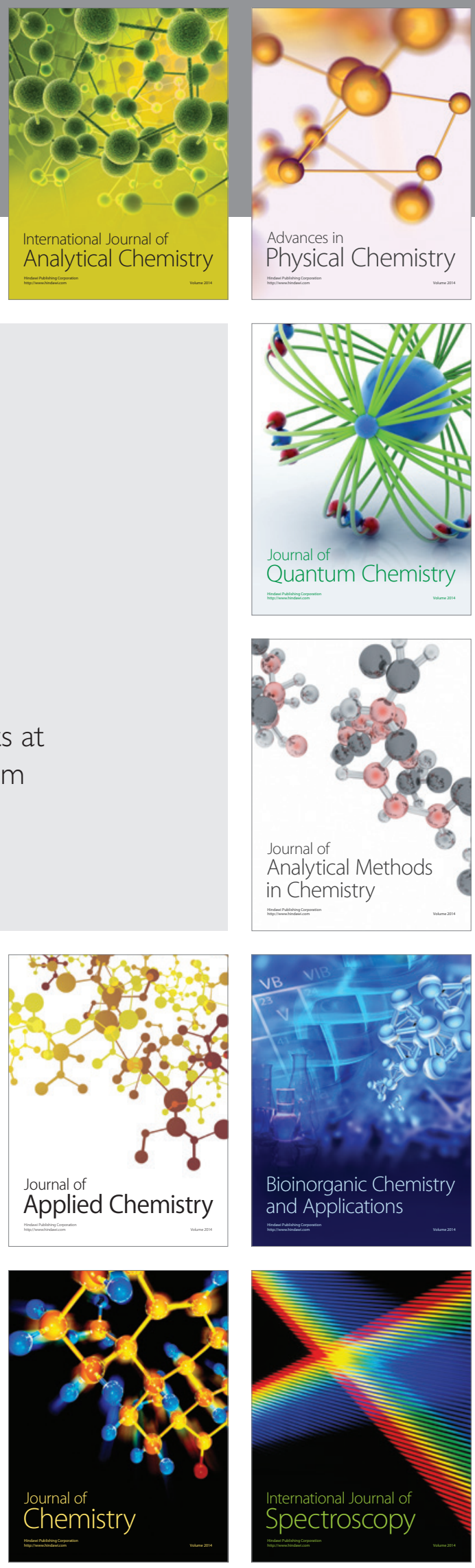